\title{
Development of a Didactic Online Course Concept for Heterogeneous Audience Groups in the Context of Healthcare IT
}

\author{
Matthias KATZENSTEINER ${ }^{\mathrm{a}, 1}$, Stefan VOGEL ${ }^{\mathrm{b}}$, Jens HÜSERS ${ }^{\mathrm{c}}$, Jendrik RICHTER ${ }^{\mathrm{b}}$, \\ Johannes HÖLKEN ${ }^{\mathrm{d}}$, Natalia LESNIEWSKA ${ }^{\mathrm{e}}$ and Oliver J. BOTT ${ }^{\mathrm{a}}$ \\ ${ }^{a}$ University of Applied Sciences and Arts Hanover, Germany \\ ${ }^{b}$ Department for Medical Informatics, University Medical Center Göttingen \\ ${ }^{c}$ Health Informatics Research Group, University AS Osnabrück, Germany \\ ${ }^{d}$ University of Applied Sciences and Arts Hildesheim/Holzminden/Göttingen, \\ Gesundheitscampus Göttingen \\ ${ }^{e}$ Digital Learning and Teaching, University of Göttingen
}

\begin{abstract}
Building a well-founded understanding of the concepts, tasks and limitations of IT in all areas of society is an essential prerequisite for future developments in business and research. This applies in particular to the healthcare sector and medical research, which are affected by the noticeable advances in digitization. In the transfer project "Zukunftslabor Gesundheit" (ZLG), a teaching framework was developed to support the development of further education online courses in order to teach heterogeneous groups of learners independent of location and prior knowledge. The study at hand describes the development and components of the framework.
\end{abstract}

Keywords. Didactic, Health IT, Citizens, eLearning, Digitalization, Digitization, Patient empowerment

\section{Introduction}

Digitalization is reaching all areas of society. [1] Not only since the Corona crisis has it become apparent that IT systems, as well as IT competencies, more and more unfold themselves as basic requirements for everyday work, personal comfort, and healthcare, e.g. in the guise of video conferences, kinds of tracking systems, or smart home and ambient assisted living infrastructures. A sensitive approach to these issues is required. $[1,2]$ Therefore, society must be empowered to understand IT, its concepts, and limits. $[1,2]$ For this, a learning program, and a continuous learning process for digital competencies are required for citizens throughout society. [3] Especially in the health sector, the IT empowerment of health care professionals and especially patients could contribute to new ways of care and supervision in the future. [4]

${ }^{1}$ Corresponding Author, Matthias Katzensteiner, University of Applied Sciences and Arts Hanover, Expo Plaza 12, 30539 Hanover, Germany; E-mail: Matthias.Katzensteiner@hs-hannover.de 
In this research study, we address how a teaching and learning concept should be designed in order to provide such a heterogeneous group of learners with competences for digitalization.

\section{Methods}

The Zukunftslabor Gesundheit (ZLG) is a transfer project focusing at digitization in health care. Its educational subproject aims to spread the gathered knowledge from the other co-projects within medical and medical informatics professionals, patients and the general public alike based on online teaching. To understand the needs of this audience in terms of didactic concepts, we split them into coherent sub-groups using the following characteristics to describe them further: Sociographic factors as age, gender, place of residence, and family status. Psychographic factors as motivation, potentials, expectations, strengths, and weaknesses. Educational factors as educational background, an affinity for (digital) media, learning type, and discussion type. [5] These factors only partially describe the target groups. Therefore, we additionally used the sinus milieu model, a market research tool, to narrow down the groups even further. [6]

With this description of our targeted audience groups, we started to adapt common models of modern online didactic, esp. the five-stage model by Gilly Salmon [7], to their needs and to the planned content of our courses. Based on all these factors and models, we then selected the tools needed to build effective eLearning courses.

All courses are to be taught twice during the project period. With the evaluation concept, we aim at fine-tuning the didactic concept, understanding of the audience and course concepts with each iteration.

\section{Results}

\subsection{Audience Groups}

We divided the heterogeneous target group in four main audience groups:

Citizens and Interested Public to emend their digital and media literacy with respect to digitization in healthcare. Members of this group will participate voluntarily and therefore have a strong intrinsic motivation to learn about current developments in the digital health sector.

Patients, their carers and relatives are directly affected as potential end-users to emend their digital and media literacy regarding digitalization in healthcare. This group has a strong extrinsic motivation to learn about current specific (w.r.t their disease) developments in the digital health sector.

Healthcare Professionals as potential users of research results and prototypes of the ZLG will also benefit from the courses. Depending on the profession, members of this group will face new technologies and will have to implement new evidence in their daily job routines.

Medical informatics professionals to empower them to use the ZLG research results for further research and development.

The latter two groups allow for a relatively fine-grained description in terms of psychographic and educational factors. These descriptions are well known from experiences in using eLearning for university teaching. However, this is not the case for 
the sub-groups of the general public. Here we had to develop an open didactic concept that is also suitable for addressing these heterogeneous groups.

\subsection{The ZLG Didactic Core Concept (ZLG-DCC)}

The development and implementation of an online course is time-consuming and characterized by many influencing factors. For our core didactic concept, we have limited our focus to four such factors: group size, group dynamics and communication, learning and working phases, as well as type and scope of supervision.

Based on these influencing factors, an adapted course structure was developed as a template (see Figure 1) according to the didactic concepts of Gilly Salmon [7] and the HiGHmed teaching project [8,9], which should support the development of online courses.

One main element of the template are so-called E-tivities. According to Gilly Salmon [7], E-tivities are standardized in the structure: introduction, objective, task, discussion. With the E-tivites, a constructivist approach to learning is followed step-bystep, starting with the pure exchange of information, to the construction of knowledge and finally to personal development.
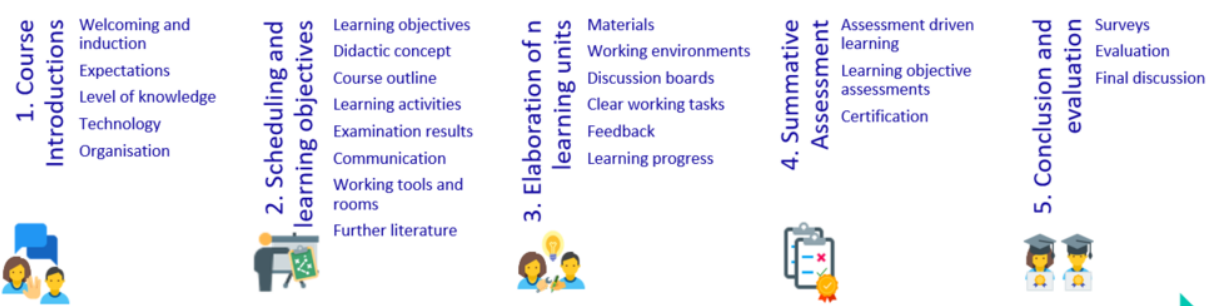

\section{Five Stage Model for Online-Teaching in ZLG}

Figure 1. Five Stage Model for Course Template ZLG based on [7-9].

The template for course development contains five essential phases, each of which has to be prepared by the lecturer.

The first phase provides a shallow course introduction in which learners get to know the new learning environment, the other learners, and the lecturers. Organizational as well as technical framework conditions are clarified, but also expectations and the knowledge level of the participants play a role in this phase.

In the second phase, the course schedule and the learning objectives to be achieved by the participants are communicated. The contents of the course also concern the expected performance of the participants but also of the lecturers.

Phase three is the core of the didactic concept in which the participants go through $n$ learning units, each of which is designed through topic-related tasks, i.e. in the form of E-tivities. The control of the achieved goals through the fulfillment of the tasks takes place in phase four.

The last phase is dedicated to evaluation, lessons learned and a wrap-up discussion.

Depending on the target group, the size of the learning group and the scope of the course, the ZLG-DCC is used in a reduced form. 


\subsection{Tools}

The concept demands tools for content management and sharing as well as interacting with participants. A suitable learning management tool (LMS) is the key to deliver these requirements. For the presented concept, the LMS should support user management (to provide access to the content), a forum (enabling interaction between participants and lecturers), provide methods to present content (e.g., learning modules) and features for surveys and exams. Offering additional synchronous interactions to students through the LMS, e.g., video conferencing and chats, promises to engage and motivate participants in an asynchronous learning environment.

In ZLG we gathered 32 requirements in total to assess and evaluate different LMS. In the end, ILIAS ${ }^{2}$ was selected. For synchronous interaction, BigBlueButton ${ }^{3}$ (BBB) was designated as video conferencing tool for data protection reasons.

For the creation of online teaching material, even more tools (e.g. video cutting and editing) might be useful, but are out of scope of this presentation.

\subsection{Evaluation}

In general, evaluation of educational programs aims to monitor the quality by the participants [10]. The evaluation results then serve as the foundation for further course development. The ZLG courses are conducted at least twice during the project. Thus, the evaluation is an integral part of each course to edit the courses according to the participant's feedback to improve their quality.

We designed an evaluation framework, from which different evaluation strategies can be derived. The framework considered three dimensions: type, method, and objects of evaluation. The following section will briefly introduce them.

First, the evaluation type defines if the evaluation is formative, i.e., ongoing throughout the running course, or summative, i.e., final assessment when the course ends. Second, the evaluation method is either quantitative or qualitative. Both methods offer distinct advantages, e.g., to openly assess the subjective experiences of learners with more degrees of freedom, qualitative evaluation should be preferred [11]. However, if we want to assess general satisfaction in a standardised way, a quantitative survey may better meet the need of the evaluation goals. Third, the evaluation object focuses on the evaluated entity, e.g. course content, teachers and E-tivities.

From this framework, we derived a core evaluation that is part of each ZLG educational program. The core evaluation allows monitoring of the course quality across the ZLG. However, the standardized toolbox also supports course developers in extending the core evaluation and designing an evaluation plan to meet their specific needs.

\section{Discussion}

The didactic concept outlined poses various challenges, from creating of a learning course to its implementation and evaluating of the participants' performance and the course quality. The strength of the concept lies in the individual discussion and

\footnotetext{
${ }^{2}$ https://www.ilias.de/

${ }^{3}$ https://bigbluebutton.org/
} 
interdisciplinary exchange in a learning group. In this context, the E-tivities form a common thread, which form a starting point for further targeted development. At the same time, however, the concept also has the weakness of being rolled out in groups of up to a maximum of 30 people per lecturer, leading to challenges when demand is high. Nevertheless, the e-learning format offers the possibility of location-independent learning. A special aspect of the concept is the creation of a common understanding of the teaching contents for the broad and heterogeneous target group of the didactic concept. For the first courses at the ZLG the particular challenge will be to prepare academic, technical but also political topics in a way that the topics can be conveyed in a captivating way and the participants are empowered and sensitized.

\section{Conclusion}

The first version of the ZLG educational framework is finalized. In the current project phase, the first courses are being developed by the lecturers in order to start the first course implementations in 2022. The course topics will be based on the other working groups of the ZLG and should thus become the bridge between research and society. The first courses will address the topics "The learning healthcare system: How it learns! Secondary use of Clinical Data for Medical Research" and "Sensor technology in patient support: application examples, perspectives and current research". Citizens in particular are to be addressed as audience members in the first phase. As a further subdivision of the target group, students in upper secondary education have been envisaged. All ZLG courses will be evaluated based on a common evaluation set to establish comparability between the course implementations and to further improve the courses.

\section{Acknowledgement}

The ZLG is funded by the Lower Saxony Ministry of Science and Culture under grant number ZN3491 within the Lower Saxony "Vorab" of the Volkswagen Foundation and supported by the Center for Digital Innovations (ZDIN).

We thank Ursula Hübner, Dagmar Krefting, Christoph Russmann and Marcus Wuttke for their support during the development of the ZLG-DCC.

\section{References}

[1] Vuorikari R, Punie Y, Carretero Gomez S and Van Den Brande G. DigComp 2.0: The Digital Competence Framework for Citizens. Update Phase 1: the Conceptual Reference Model. EUR 27948 EN. Luxembourg (Luxembourg): Publications Office of the European Union; 2016. JRC101254

[2] Meskó B, Drobni Z, Bényei É, Gergely B, Győrffy Z. Digital health is a cultural transformation of traditional healthcare. Mhealth. 2017;3:38. Published 2017 Sep 14. doi:10.21037/mhealth.2017.08.07

[3] Pettersson, F. On the issues of digital competence in educational contexts - a review of literature. Educ Inf Technol 23, 1005-1021 (2018). https://doi.org/10.1007/s10639-017-9649-3

[4] Calvillo J, Román I, Roa LM. How technology is empowering patients? A literature review. Health Expect. 2015;18(5):643-652. doi:10.1111/hex.12089

[5] Köhn-Ladenburger C. Marketing für LOHAS. Wiesbaden: Springer Fachmedien Wiesbaden; 2013. S. $12-21$ 
[6] Barth B, Flaig BB, Schäuble N, Tautscher M, Hrsg.: Praxis der Sinus-Milieus ${ }^{\circledR}$ : Gegenwart und Zukunft eines modernen Gesellschafts- und Zielgruppenmodells. Wiesbaden: Springer VS; 2018. available at : http://dx.doi.org/10.1007/978-3-658-19335-5.

[7] Gilly Salmon, E-Moderating: The Key to Online Teaching and Learning Paperback, Routledge; 2nd edition (19 July 2013)

[8] education.highmed.org [Internet]. HiGHmed Teaching and Training Programme for Medical Informatics [last checked: 07.09.2021]. available: https://education.highmed.org

[9] Witte ML, Behrends M, Benning NH, Hoffmann I; HiGHmeducation Consortium, Bott OJ. The HiGHmed Didactical Framework for Online Learning Modules on Medical Informatics: First Experiences. Stud Health Technol Inform. 2020 Jun 26;272:163-166. doi: 10.3233/SHTI200519. PMID: 32604626.

[10] Baldwin, Sally J. \& Trespalacios, Jesús (2017). Evaluation instruments and good practices in online education. Online Learning 21 (2) doi: 10.24059/olj.v21i2.913

[11] Ghislandi P, Raffaghelli JE, Sangrà A, Ritella G. The Street Lamp Paradox: Analysing Students' Evaluation of Teaching through Qualitative and Quantitative Approaches. ECPS - Educational Cultural and Psychological Studies. 2020. DOI: 10.7358/ecps-2020-021-ghis 